\title{
Innovative and Energy Efficient Smart Window Based on Nanomaterial Technologies
}

\author{
Rudra Sankar DHAR ${ }^{1,2^{*}}$, Abdulhakem ELEZZABI ${ }^{2}$, and Mohamed AL-HUSSEIN ${ }^{1}$ \\ ${ }^{1}$ CNRL Natural Resources Engineering Facility, Department of Civil and Environmental \\ Engineering, University of Alberta, Edmonton, Alberta, T6G 2W2, Canada \\ ${ }^{2}$ Ultrafast Optics and Nanophotonics Laboratory, Department of Electrical and Computer \\ Engineering, University of Alberta, Edmonton, Alberta, T6G 2V4, Canada \\ *e-mail: rdhar@ualberta.ca
}

\begin{abstract}
Strategies for incorporating energy-efficiency requirements into building standards have been implemented by governments in developed countries in order to introduce the concept of green nanotechnology. Substituting regular glass windows in residential/commercial buildings with smart windows is the objective. This paper describes the development of innovative nanomaterial based membranes/coatings for smart windows that would work as electric dimming glass. Currently, curtains and blinds function to block sun light; eliminating such elements is of importance due to its limited functionality (e.g. blocking UV prevents sun light illumination), health (e.g. dust and germ collection especially in hospitals), disposal/recycling issues, cost, and maintenance. The proposed smart window is expected to block harmful UV light and provide a controlled privacy. Electrochromic smart windows are already in use and are able to vary their throughput of visible light and solar energy by application of electrical voltage and are able to provide energy efficiency and indoor comfort in buildings. These smart windows comprises of electrochromic materials such as $\mathrm{Li}_{\mathrm{x}} \mathrm{WO}_{2.89}$ and $\mathrm{H}_{\mathrm{x}} \mathrm{NiO}_{2}$ as cathodic and anodic oxide films, respectively, and other complex polymers, which are complicated to create, expensive and some are hazardous in nature. Nanocellulose (achieved from wood/pulp product) is already being used in flexible electronics, so nanomaterial membrane for smart window is a probable alternative. This paper presents an innovative technology for smart-windows, utilizing nanocellulose fiber (abundantly available) doped with conductive nanoparticles (work as dimming glass on voltage application), mixed with minute amount of electrochromic material form thin film membranes.
\end{abstract}

\section{KEYWORDS}

Nanocellulose, electrochromic, electric dimming glass, smart windows, nanomaterial

\section{INTRODUCTION}

The smart windows are able to control the throughput of visible light and solar radiation into buildings as an electric dimming glass (EDG) while it can convey energy efficiency as well as human comfort by changing the transmittance levels depending on dynamic needs. Smart windows are currently being used in some high-tech commercial buildings, as shown in Figure 1 with two examples of multi-pane installations in which some panes are in their fully colored state and others are bleached. Thus the smart windows in Figure 1 induce both colored and bleached states simultaneously presenting switchable and controlled privacy. These smart windows utilize electrochromism and prompt the concept of "green" nanotechnologies that are very much in focus in today's scientific community [1-3]. 


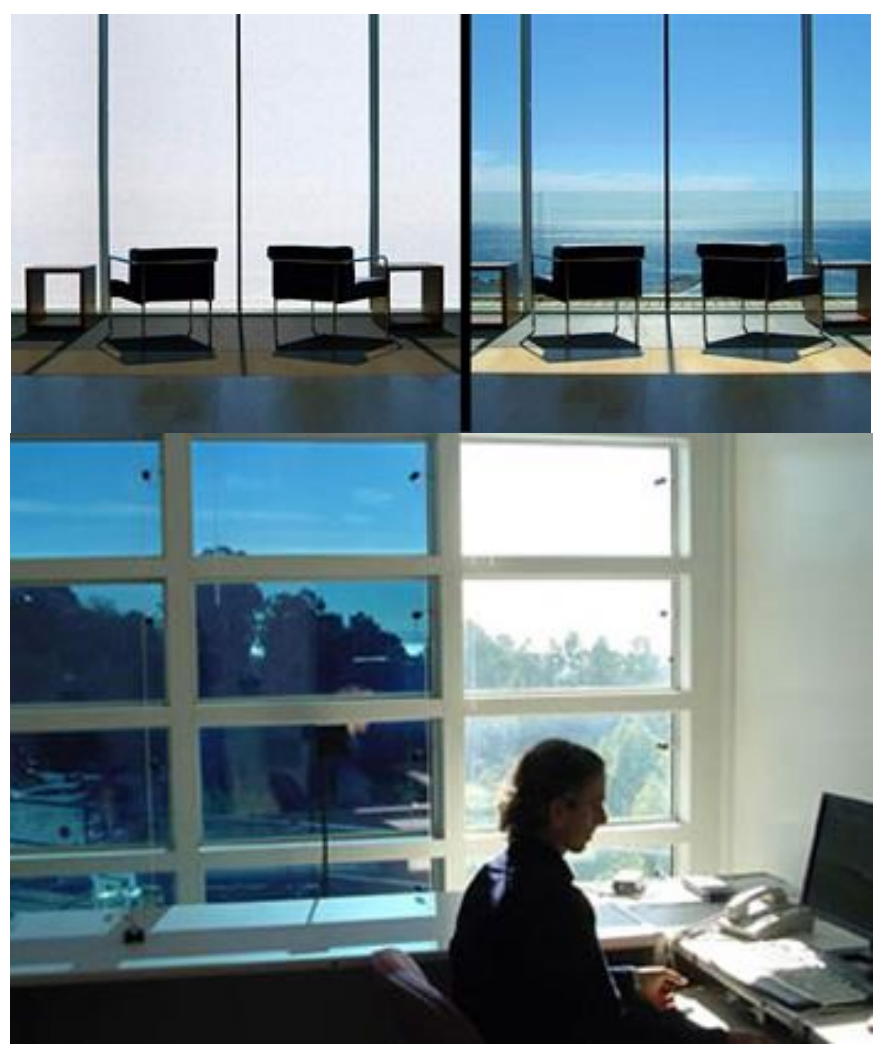

Figure 1. Two examples of electrochromic smart windows each having both the fully colored and the bleached state [3].

The smart windows developed with integrated technology and photovoltaics can provide advantage of around $20 \%$ savings in energy consumption while having the transmittance similar to regular glass windows [4-7]. In regular glass windows direct sunlight enters the premises during summer months leading to increase in indoor temperatures; while in winter the glass absorb the cold from outside and cool the premises more than desirable. To maintain comfortable temperature, climate controlling is done by air conditioning and heating thus increasing power consumption. And especially in Canada where extreme weather presumes, power consumption is a major issue. So, climate control based smart windows that can maintain comfortable and suitable temperature in buildings are desired. The smart windows operate on the basic concept of EDG, a technology used to control transmission of daylight and provide privacy [5]. The major technologies that emerge for smart windows are: suspended-particle-device (SPD) and electrochromic (EC) device [7].

SPD smart window is constructed by using two panes of glass separated by a conductive film with suspended light absorbing nanoparticles. This technology is under research. Nanoparticles like iron oxide along with nanocellulose may be used to be suspended in liquid/film such as in acetone/silicone oil/ propylene carbonate. At no electrical bias, nanoparticles absorb light, making the glass dark [8, 9]. On application of bias, particles align and light passes through. The amount of light passing through the SPD-window is precisely controlled with electrical voltage. Figure 2, illustrates the working concept of SPD. However, the major advantage is that SPD switches "ON" in 1-3 seconds and is expected to provide $99 \%$ UV blockage promising energy saving [6]. 

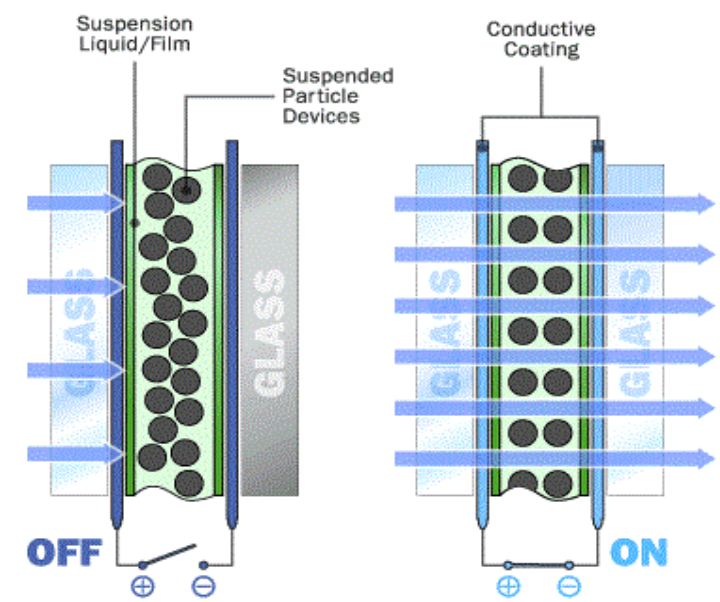

Figure 2. SPD based smart technology presenting the on/off process [8].

A competing technology with SPD smart windows is the electrochromic smart window. Electrochromic windows consist of two glass panes with several layers sandwiched in between (as shown in Figure 3 (a) and (b)) under Off-and-On conditions. The most commonly used electrochromic materials in between glass panes are tungsten oxide $\left(\mathrm{WO}_{3}\right)$, niobium oxide $\left(\mathrm{NbO}_{\mathrm{x}}\right)$ or even violegens with titanium oxide $\left(\mathrm{TiO}_{2}\right)$. On application of electrical bias across nanoscopically-thin coating on the glass surface the electrochromic layer is activated, which changes color from clear to dark i.e translucent states (usually dark blue), and the transparency level changes with bias [4, 8]. Different from SPD, electrical charge is applied one time $(\sim 1$ Volt) to change the property of the thin film. Applying a reversed charge the glass returns to its original state. This dimming process moves slow from the edges taking a time that is varied between many seconds to minutes (depending on windows size) [8, 10]. Electrochromic glass window provides comforting level of visibility even in the darkened state. These smart windows require electricity to change its opaqueness and are energy based solution, so cost involved and difficult to commercialize for regular buildings [4, 8]. Though, electrochromic material based smart window is still in the developing state and further research is needed, these materials are extremely expensive hence being difficult to commercialize. Also the construction of this window is complex and the material has low life time thus again increasing cost.

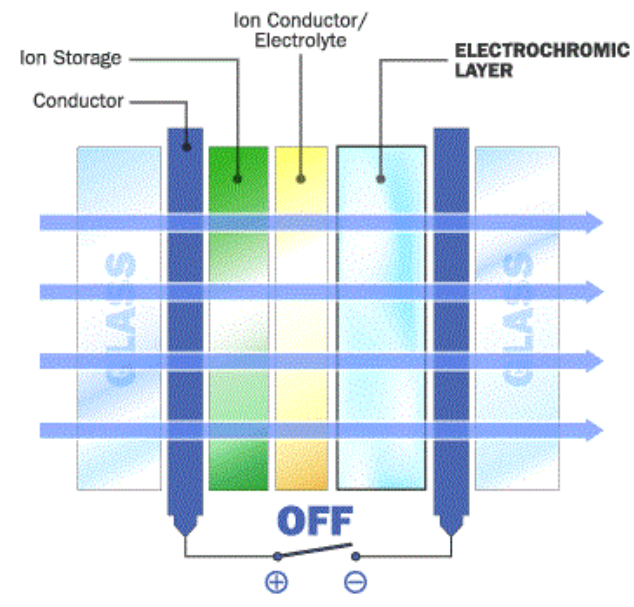

(a)

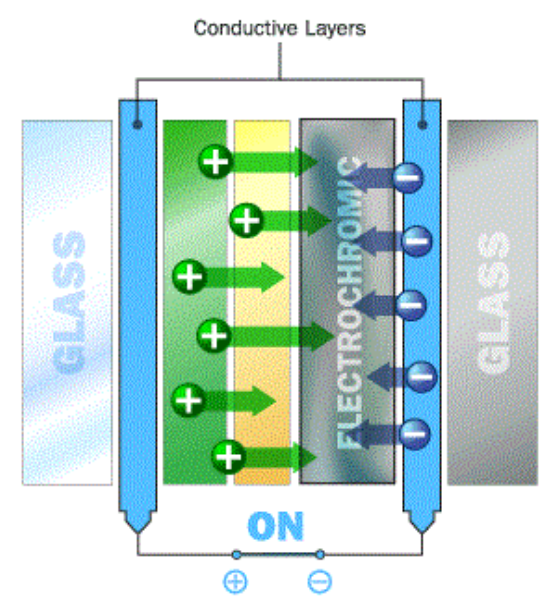

(b)

Figure 3. Electrochromic smart windows presenting the (a) off and (b) on processes [8]. 
As much as 30 to $40 \%$ of the primary energy in the world is spent in buildings, for heating, cooling, lighting, ventilation and appliances, and developed countries lie at the top of this bracket; the fraction of the electricity used in buildings is even higher and can amount to $~ 70 \%$ $[3,11]$. The need for smart energy efficient window is clear and must function in harmony with nature and make good use of what nature offers in terms of light and energy. Hence, we describe a fully functional electrochromic material technology based smart window consisting of $\mathrm{Li}_{\mathrm{x}} \mathrm{WO}_{2.89}$ and $\mathrm{H}_{\mathrm{x}} \mathrm{NiO}_{2}$ as cathodic and anodic oxide films that work as electric dimming glass. Finally we propose a combined (SPD and EC) technology utilizing nanocellulose fiber and conductive nanoparticles forming nanomembranes to develop an energy-efficient smart-window.

\section{ELECTROCHROMIC SMART WINDOW}

A generic design for an EC device is introduced which has a construction consistent with that of a thin film electrical battery whose charging state corresponds to a certain level of optical absorption. Figure 4 presents a generic EC device with five layers positioned between two transparent substrates (glass) [3, 12]. The five layers principally comprises of three different kinds of layered materials: The ion conductor (electrolyte) separates the two EC films (active electrochromic layer and counter electrode) that conducts ions and electrons. This counter electrode is also known as the optically passive ion storage film. The transparent conductors are pure electron conductors. Optical absorption occurs when electrons move into the EC film(s) from the transparent conductors along with charge balancing ions entering from the electrolyte. Ion transport is easiest for small ions and protons $\left(\mathrm{H}^{+}\right)$or lithium ions $\left(\mathrm{Li}^{+}\right)$are used in the majority of all practical EC devices [3].

There are two different kinds of EC oxides: referred as "cathodic" that color under ion insertion, and as "anodic" that color under ion extraction. It is highly advantageous to combine the "cathodic" oxide (for example based on $\mathrm{W}, \mathrm{Mo}$, Ti or $\mathrm{Nb}$ ) and the "anodic" oxide (for example based on $\mathrm{Ni}$ or Ir) as two EC films in a smart window [3]. Applying a voltage in order to transport ions between the two EC films in one direction makes both of these films color, and ion transport in the other direction makes both of them bleach [3]. The most commonly used oxides are based on $\mathrm{W}$ and $\mathrm{Ni}$ exhibiting cathodic and anodic electrochromism, respectively. On addition of proton to this anodic oxide $\mathrm{H}_{\mathrm{x}} \mathrm{NiO}_{2}$ is formed that provides coloring anodically. The pure oxides are characterized by unoccupied $t_{2 g}$ states ( $\mathrm{d}$ level as per the energy band structure is split in two upper state $e_{g}$ and lower state $t_{2 g}$ ), and insertion of ions and electrons may fill these states to the top of the band so that the material exhibits a gap between the $e_{g}$ and $t_{2 g}$ levels. The material then becomes transparent, assuming that the band gap is wide enough [3, 12]. Pure tungsten oxide $\left(\mathrm{WO}_{3}\right)$ has full $\mathrm{O} 2 \mathrm{p}$ band while an empty $\mathrm{d}$ band and is transparent, as is applicable for any wide band gap semiconductor. Addition of protons and charge balancing electrons to this tungsten oxide produce $\mathrm{H}_{\mathrm{x}} \mathrm{WO}_{3}$ that provides a partial filling of the $\mathrm{d}$ band, leading to optical absorption as discussed for nickel oxide. Addition of $\mathrm{Li}^{+}$instead of $\mathrm{H}^{+}$, onto $\mathrm{WO}_{3}$ by electrochemical intercalation increases the optical absorption and shifts the peak position somewhat towards higher energies. A broad absorption band develops at an energy around $\sim 1.5 \mathrm{eV}$ for the lower values of $\mathrm{x}$, while the dominant absorption moves toward higher energies for large intercalation levels $[3,13] . \mathrm{Li}_{\mathrm{x}} \mathrm{WO}_{2.89}$ for $\mathrm{x}$ in between 0.3 to 0.35 is found well suited as a cathodic oxide (active electrochromic) while $\mathrm{H}_{\mathrm{x}} \mathrm{NiO}_{2}$ as an anodic oxide (counter electrode) based EC films providing long-term cycling durability [3]. 


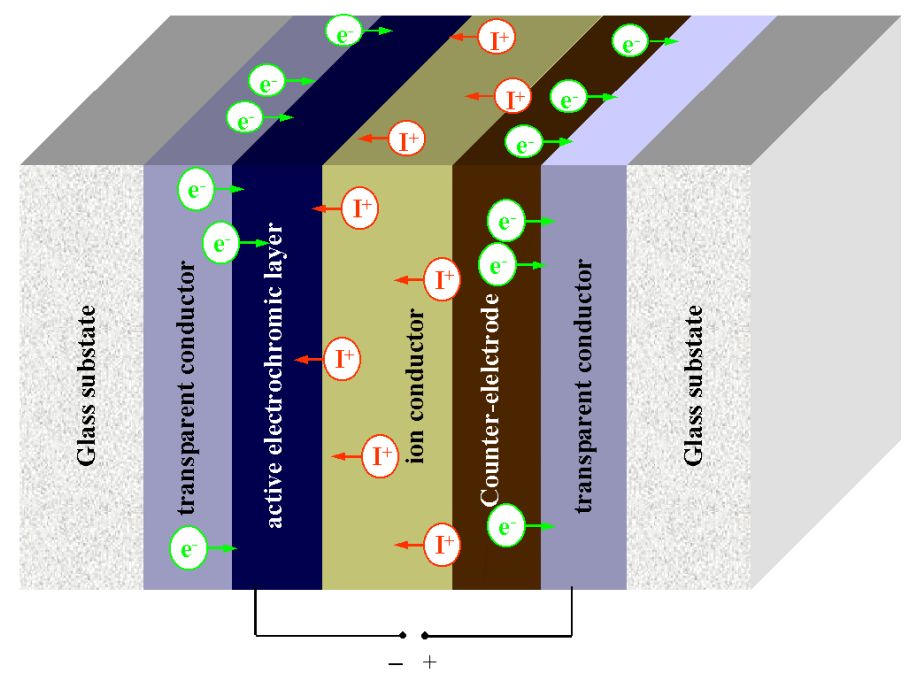

Figure 4. Generic five-layer electrochromic smart window device on application of bias.

The EC device includes two transparent conductors on either side in between the glass substrate and the electrochromic layer. The transparent electrical conductors may well be the most expensive part in an EC smart window, so deserves much attention [3]. Transparent electrical conductors are of large interest not only for electrochromics but also for thin film solar cells, light emitting devices, display devices of various types, etc. Thin films of heavily doped transparent conducting oxides are most commonly used as electrodes in EC devices. Several of the oxide materials are able to combine a resistivity as low as $\sim 1 \times 10^{-4} \Omega \mathrm{cm}$, a value of $\mathrm{T}_{\text {lum }}$ which is only a few percent in a film with a thickness that is large enough $(\sim 300 \mathrm{~nm})$ to give an adequate resistance per square, and excellent durability. ITO films are very widely used as transparent conductor, but tend to be expensive as a result of the high price of indium. ITO films prepared by adequately controlled reactive dc magnetron sputtering onto glass typically yield resistivity as low as $\sim 2 \times 10^{-4} \Omega \mathrm{cm}$ and is considered to be suitable for the EC device [3, 14]. Electrolytes known as ion conductors are the material layer used at the junction of the two EC films and allow conduct and transport of ions and electrons across the device. Also this electrolyte needs to work as a good adhesive so as to make sure both sides are well connected and the EC device is functional. Polymer and ionic liquids based electrolyte can be used in EC devices and can lead to constructions that are rugged ion conductors [3]. In situ polymerization may be needed to avoid sealing difficulties and create practical devices such as EC smart windows, and research on polymerization for this purpose for polymer electrolytes as well as for ionic-liquid-based gel electrolytes are under process [3]. PMMA (poly-methyl-methacrylate)based electrolytes [15], ionic liquids (may show EC properties) and gel electrolytes plasticized with ionic liquids [16] are the regularly used electrolytes for EC devices.

\section{SPD SMART WINDOW}

A suspended particle device (SPD) smart window comprises a polymer layer, with a large number of polarizable particles, between two sheets of glass coated with transparent and electrically conducting thin films surrounding the polymer layer. The nanoparticles are less than $\sim 200 \mathrm{~nm}$ in size in order to avoid excessive visible haze and consist of polyiodide having strong optical anisotropy [3]. Nanocellulose fibers (CNC/NFCs) that is available abundantly from wood/paper pulp and from damaged/unused parts and portions recycling a share of bio-waste is a 
kind of inexpensive material, and is possibly best fit material for SPD smart windows. Cellulose fibers with $\sim 20 \mu \mathrm{m}$ diameter form regular paper known as nanopaper, while each fiber consists of millions of cellulose nanofibrils (NFC) with diameter of $\sim 4 \mathrm{~nm}$ and length of $\sim 2 \mathrm{~mm}$ [17]. As NFCs are smaller than the wavelength of visible light, nanopaper is highly transparent due to large light scattering in the forward direction leading to superior optical properties [17, 18]. Figure 5 (a), shows schematic of nanopaper with light scattering effect, while the optical transmittance is seen to decrease when the object is moved away from the substrate as observed in Figure 5 (b) and (c) [17]. But, successful deposition of transparent and conductive materials such as tin-doped indium oxide (ITO) or silver nanowires (AgNWs) which are similar to the transparent conductors in EC devices opens up applications in display optoelectronics, touch screens and interactive paper, thus allowing high optical transmittance [17]. This conductive ITO doped nanopaper based film is suspended in a transparent liquid such as acetone/silicone oil and bias is applied to control the light throughput, thus forming a dynamic SPD smart window.

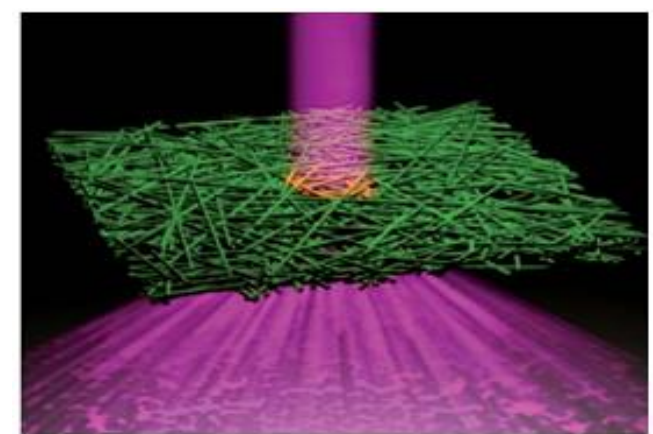

(a)

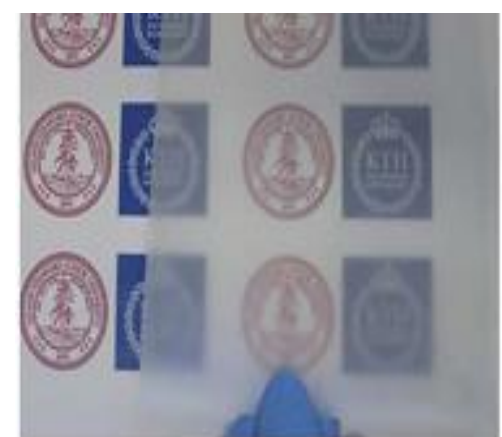

(b)

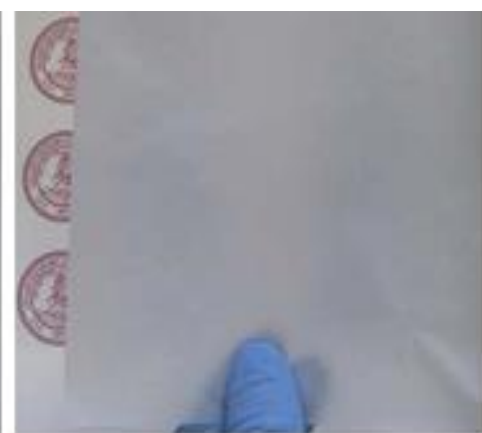

(c)

Figure 5. (a) Schematic of a nanocellulose paper indicating its light scattering effect. (b) Transparent nanopaper held close to the below object indicate high optical transparency. (c) Same nanopaper at a distance from object rarely visible indicating large light scattering [17].

\section{INNOVATIVE TECHNOLOGY SMART WINDOW}

The main goal is to introduce an innovative technology based on EC device and SPD smart windows. This smart window is expected to have the similar glass substrate on both sides while the inner side of the glass will be coated with ITO to function as transparent electrode as in both the EC devices and SPDs. The nanocellulose fibrils will be used to form nanopaper as in a SPD structure [19] and will be doped with $\mathrm{WO}_{3}$ and $\mathrm{NiO}_{2}$ forming the cathodic and anodic oxide SPD-EC films. As these thin films, ideally nanomembranes will have the electrochromic material as in an EC device is expected to function similarly on application of bias. Also as the NFCs form a conductive nanopaper will support the functionality of the EC device thus requiring less amounts of electrochromic materials in this innovative technology based smart window design. This smart window will be less costly having an innovative approach in the technology development is expected to function not only as electric dimming glass but also as an energy sustainable device, thus conserving, transforming and utilizing the solar energy (introducing green energy) for other electrical purposes in buildings.

\section{SUMMARY}

A detailed review of existing electrochromic technology based smart window has been studied. The materials and the technology that has been used for the windows have been presented. This 
smart window works as electric dimming glass but being costly cannot be used in regular residential/commercial buildings replacing the current regular glass windows. SPD technology based smart window with the use of conductive nanopaper is also presented. This paper describes the proposed development of innovative technology that combines the electrochromic material with CNCs and also combines the SPD technology with EC device technology. This new technology based smart window is to comprise nanopaper doped with minute amounts of $\mathrm{WO}_{3}$ and $\mathrm{NiO}_{2}$ electrochromic materials forming cathodic and anodic oxides, respectively. This membrane will be used with ionic liquid electrolyte forming the SPD-EC films and be implemented in smart windows thus developing an innovative and energy efficient smart window, inducing the green technology standards in structural designs.

\section{ACKNOWLEDGEMENTS}

The authors acknowledge and thank the University of Alberta and the NSERC funding for this smart window project.

\section{REFERENCES}

1. Smith, G.B., and Granqvist, C.G., (2010). Green Nanotechnology: Solutions for Sustainability and Energy in the Built Environment, CRC Press, Boca Raton, FL, USA.

2. García-Martinez, J. (2013). Nanotechnology for the Energy Challenge, 2nd ed., Wiley$\mathrm{VCH}$, Weinheim, Germany.

3. Granqvist, C. G. (2014). "Electrochromics for smart windows: Oxide-based thinfilms and devices", Thin Solid Films., Elsevier, 564, 1-38.

4. Zhou, J., Gao, Y., Zhang, Z., Luo, H., Cao, C., Chen, Z., Dai, L., and Liu, X., (2011). " $\mathrm{VO}_{2}$ thermochromic smart window for energy savings and generation", Scientific Reports, NPG, 3029, 1-8.

5. BC Hydro, (2015). "Green your home, heating", Energy-Efficient Windows, https://www.bchydro.com/powersmart/residential/guides_tips.html.

6. Horizon 2020, (2014). "News, "Smart' windows to cut energy use in buildings by 20\%", Europa, Smart Windows, http://ec.europa.eu/programmes/horizon2020/en/.

7. Sage Glass, (2014). "Smart windows open new opportunities for energy savings", smart windows, www.eco-business.com.

8. Bonsor, K., (2014). "How Smart Windows Work", green construction, http://home.howstuffworks.com/home-improvement/construction/green/smart-window.htm.

9. Vergaz, R., Sánchez-Pena, J. M., Barrios, D., Va'zquez, C., and Contreras-Lallana, P., (2008). "Modelling and electro-optical testing of suspended particle devices", Solar Energy Mat. Solar Cells, Elsevier, 92 (11), 1483-1487.

10. Llorde's, A., Garcia, G., Gazquez, J., and Milliron, D. J., (2013). "Tunable near-infrared and visible-light transmittance in nanocrystal-in-glass composites", Nature, NPG, 500, 23-27.

11. Richter, B., Goldston, D., Crabtree, G., Glicksman, L., Goldstein, D., Greene, D., Kammen, D., Levine, M., Lubell, M., Savitz, M., Sperling, D., Schlachter, F., Scofield, J., and Dawson, J., (2008). "How America can look within to achieve energy security and reduce global warming", Rev. Mod. Phys., APS, 80, S1-S103.

12. Granqvist, C.G., (1995). Handbook of Inorganic Electrochromic Materials, Elsevier, Amsterdam, The Netherlands. 
13. Berggren, L., Jonsson, J.C., and Niklasson, G.A., (2007). “Optical absorption in lithiated tungsten oxide thin films: Experiment and theory”, J. Appl. Phys., AIP, 102, 083538.

14. Ederth, J., Johnsson, P., Niklasson, G. A., Hoel, A., Hultåker, A., Heszler, P., Granqvist, C. G., Doorn, A. R. van, Jongerius, M. J., and Burgard, D., (2003). "Electrical and optical properties of thin films consisting of tin-doped indium oxide nanoparticles", Phy. Rev. B, APS, $68,155410$.

15. Reiter, J., Krejza, O., and Sedlař́ḱková, M., (2009). "Electrochromic devices employing methacrylate-based polymer electrolytes", Sol. Enrgy Mat. Sol. Cells, Elsevier, 93(2), 249-255.

16. Desai, S., Shepherd, R.L., Innis, P.C., Murphy, P., Hall, C., Fabretto, R., and Wallace, G.G., (2011). "Gel electrolytes with ionic liquid plasticiser for electrochromic devices", Electrochim., ACTA, 56, 4411.

17. Hu, L., Zheng, G., Yao, J., Liu, N., Weil, B., Eskilsson, M., Karabulut, E., Ruan, Z., Fan, S., Bloking, J. T., McGehee, M. D., Wagberg, L., and Cui, Y., (2013). "Transparent and conductive paper from nanocellulose fibers", Energy \& Environ. Sci., RSC, 6, 513-518.

18. Nystrom, G., Mihranyan, A., Razaq, A., Lindstrom, T., Nyholm, L., and Stromme, M., (2010). "A Nanocellulose Polypyrrole Composite Based on Microfibrillated Cellulose from Wood", J. Phys. Chem. B, ACS, 114, 4178-4182.

19. Miettunen, K., Vapaavuori, J., Tiihonen, A., Poskela, A., Lahtinen, P., Halme, J., and Lund, P., (2014). "Nanocellulose aerogel membranes for optimal electrolyte filling in dye solar cells", Nano Energy, Elsevier, 8, 95-102. 